\title{
THE
}

\section{The contribution of eddies to striations in absolute dynamic topography}

\author{
C. E. Buckingham \\ University of Rhode Island \\ Peter C. Cornillon \\ University of Rhode Island, pcornillon@uri.edu
}

Follow this and additional works at: https://digitalcommons.uri.edu/gsofacpubs

Terms of Use

All rights reserved under copyright.

\section{Citation/Publisher Attribution}

Buckingham, C. E., and P. C. Cornillon (2013), The contribution of eddies to striations in absolute dynamic topography, J. Geophys. Res. Oceans, 118, 448-461, doi: 10.1029/2012JC008231

Available at: https://doi.org/10.1029/2012JC008231

This Article is brought to you for free and open access by the Graduate School of Oceanography at DigitalCommons@URI. It has been accepted for inclusion in Graduate School of Oceanography Faculty Publications by an authorized administrator of DigitalCommons@URI. For more information, please contact digitalcommons-group@uri.edu. 


\title{
The contribution of eddies to striations in absolute dynamic topography
}

\author{
C. E. Buckingham, ${ }^{1}$ and P. C. Cornillon ${ }^{1}$ \\ Received 31 May 2012; revised 29 November 2012; accepted 30 November 2012; published 31 January 2013.
}

[1] Distinct 4 year averages of absolute dynamic topography reveal striations in all ocean basins during 1993-2008. Striations are alternating mesoscale jet-like structures observed in time-averaged zonal geostrophic velocity, $\bar{u}$. They are characterized by speeds $O\left(1 \mathrm{~cm} \mathrm{~s}^{-1}\right)$ and are nominally separated by $200 \mathrm{~km}$ in the meridional direction. Similar patterns have been observed in sea level anomaly, mean dynamic topography, and Argo float measurements. Use of a tracked-eddy database in concert with a contour identification and eddy removal algorithm demonstrates that eddies are a dominant source of striations in $\bar{u}$ in the South Pacific $\left(20^{\circ} \mathrm{S}-50^{\circ} \mathrm{S}, 200^{\circ} \mathrm{E}-280^{\circ} \mathrm{E}\right)$. Eddies with lifetimes $\geq 4$ weeks account for $46-57 \%$ of the variance in $\bar{u}$ and correlation coefficients between total and eddy-only $\bar{u}$ are $0.90-0.93$. Attention is given to the ability of the algorithm to correctly identify eddies and suggests that a more appropriate bound on the variance due to eddies is $\sim 30-70 \%$. This permits the existence of latent zonal jets and/or $\beta$-plumes. Additional findings of the study include (1) a large number of eddies having a broad range of amplitudes and scales contribute most to the eddy-induced patterns and (2) the standard deviation of $\bar{u}$ does not decay inversely with averaging period as proposed by a model of random eddies.

Citation: Buckingham, C. E., and P. C. Cornillon (2013), The contribution of eddies to striations in absolute dynamic topography, J. Geophys. Res. Oceans, 118, 448-461, doi:10.1029/2012JC008231.

\section{Introduction}

[2] Geostrophic turbulence predicts zonal jets in the ocean and atmosphere. Under this theory, energy cascades from small to large scales while enstrophy-i.e., squared vorticity - cascades from large to small scales. The combined effects of the latitudinal variation in the Coriolis parameter and the inverse and forward cascades of energy and enstrophy, respectively, are thought to result in multiple zonal jets (MZJs) [Rhines, 1975]. Another theoretical framework for the existence of zonal jets in the ocean is secondary instability theory [Pedlosky, 1975; Berloff et al., 2009].

[3] Until recently, MZJs had not been observed in the global ocean. While numerical models consistently produced patterns supporting the existence of MZJs on the Earth [e.g., Williams, 1978; Maltrud and Vallis, 1991; Panetta, 1993; Treguier and Panetta, 1994; Cho and Polvani, 1996; Nakano and Hasumi, 2005], observational support for the existence of zonal jets in the ocean have typically been confined to regional studies such as those in equatorial waters [Firing, 1987; Gouriou et al., 1987], the Brazil Basin [Hogg and Brechner Owens, 1999], and the Southern Ocean [Nowlin and Clifford, 1982; Orsi et al., 1995; Sokolov and Rintoul, 2007].

\footnotetext{
${ }^{1}$ Graduate School of Oceanography, University of Rhode Island, Narragansett, Rhode Island, USA.

Corresponding author: C. E. Buckingham, Graduate School of Oceanography, University of Rhode Island, South Ferry Road, Narragansett, RI 02874, USA. (cbuckingham@gso.uri.edu)

(C)2012. American Geophysical Union. All Rights Reserved. 2169-9275/13/2012JC008231
}

However, it was not until 2005, and again in 2008, that patterns resembling MZJs were observed on a global scale [Maximenko et al., 2005, 2008]. In their 2005 study, Maximenko and coauthors created a time-average of sea level anomaly (SLA) and illustrated the existence of zonallycoherent, mesoscale alternating currents in all of the world's oceans. Maximenko and coauthors further demonstrated the existence of stationary jet-like structures in mean dynamic topography (MDT) in their 2008 study. The jet-like structures were referred to as "striations", in light of uncertainty surrounding the physics of these phenomena. An example of striations is shown in Figure 1a.

[4] Subsequent studies have examined striations from various points-of-view. Notable ones include those by Centurioni et al., [2008] and Ivanov et al. [2009, 2010] in the California Current System and van Sebille et al. [2011] in the North Atlantic. The latter describes striations using a three-dimensional reconstruction of the density field from Argo profiling floats, while the former uses altimeter-based measurements to examine striations. In addition, a recent study by Cravatte et al. [2012] documented a series of zonal jets at intermediate depth near the equator by averaging drift velocities of Argo floats at parking depths of 1000 and $1500 \mathrm{~m}$. All studies suggest the existence of zonally-coherent structures in time-averaged zonal geostrophic velocity. Most studies document quasi-stationary striations, although there is some evidence for a slight meridional migration of patterns [Ivanov et al., 2009]. In addition, both Huang et al. [2007] and Scott et al. [2008] investigated measures of anisotropy for the upper ocean and found that the geostrophic velocity 

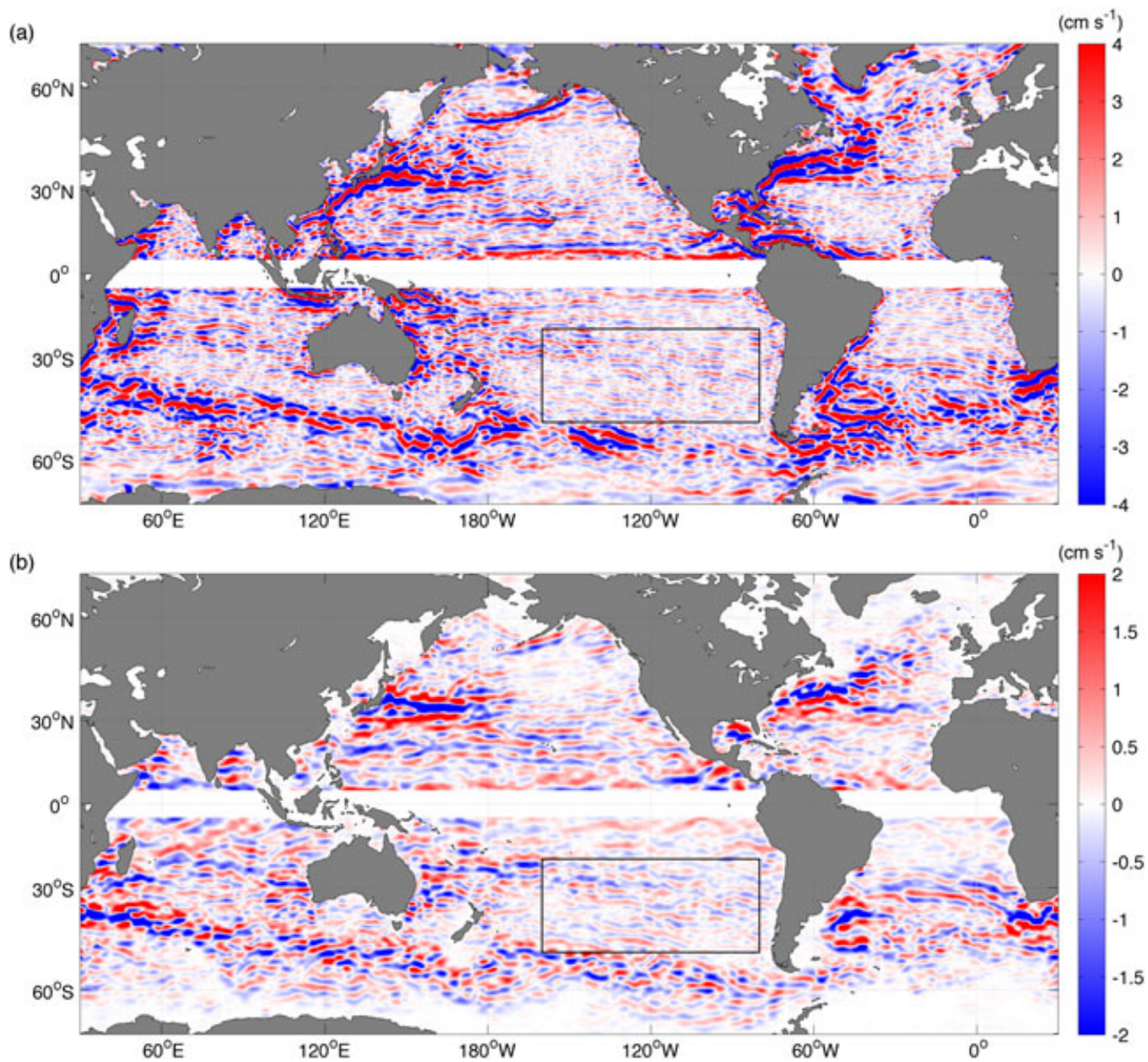

Figure 1. Global maps of time-averaged zonal geostrophic velocity, $\bar{u}$, estimated from (a) observed and (b) simulated SSH, 1993-1996. Observed SSH consist of AVISO/CLS ADT and were spatially high-pass-filtered prior to estimating zonal geostrophic velocity. Simulated SSH were obtained by superimposing Gaussian eddies with amplitude, scale, position, and lifetime identically specified by the eddy database [CCS2011] onto an otherwise flat ocean. Black boxes denote the region examined in this study $\left(20^{\circ} \mathrm{S}-50^{\circ} \mathrm{S}, 200^{\circ} \mathrm{E}-280^{\circ} \mathrm{E}\right)$.

field, when averaged in time, has a greater degree of zonal variance than meridional variance. It is also noteworthy that patterns similar to striations have been observed in front probability estimated from microwave sea surface temperature (SST) [Buckingham and Cornillon, 2010], scatterometer estimates of surface winds [Maximenko et al., 2010; Divakaran, 2011], and reanalysis of the southeast Indian Ocean [Divakaran and Brassington, 2011].

\subsection{General Interpretation of Striations}

[5] Striations have generally been interpreted as jets [Maximenko et al., 2005; Ivanov et al., 2009; van Sebille et al., 2011; Kamenkovich et al., 2009; Berloff et al., 2009; Cravatte et al., 2012]. Such jets have been described as quasi-zonal in reference to their deviation from strictly zonal flow [Ivanov et al., 2009; van Sebille et al., 2011; Wang et al., 2012] and latent in reference to their small amplitude relative to the background eddy field [Berloff et al., 2011]. Hristova et al. [2008] suggested that radiating instabilities of an eastern boundary current could act as a source of zonal jets for the interior ocean. This idea was extended by Wang et al.
[2012] using a simple, nonlinear barotropic quasi-geostrophic model. The authors found that nonlinear interactions are essential in the maintenance of jet-like features emanating from the eastern boundary. A related interpretation is that striations are the result of $\beta$-plumes radiating from the eastern boundary [Centurioni et al., 2008; Melnichenko et al., 2010; Afanasyev et al., 2012; Di Lorenzo et al., 2012]. The concept is that processes on the eastern side of the basin radiate Rossby waves and generate coherent vortices through baroclinic instability. The anomalies propagate westward under the influence of $\beta$ and create striations. In this model, striations are the manifestation of both eddies and jet-like structures emanating from the eastern boundary.

[6] While it is tempting to interpret striations as jets, Schlax and Chelton [2008] caution against this. They argue that westward-propagating anomalies with completely random positions create patterns similar to those observed. Developing a model of westward-propagating Gaussian eddies with amplitudes, scales, lifetimes, and propagation speeds characteristic of observed eddies, Schlax and Chelton [2008] demonstrated that random eddies can create striations 
in time-averaged sea surface height (SSH) and the associated time-averaged zonal geostrophic velocity field, $\bar{u}$. In their model, eddies of large amplitude and scale contribute most to the observed striations and the standard deviation of $\bar{u}$ decays inversely with averaging period. To help illustrate this mechanism, we display in Figure 2 how an anticyclonic eddy can create striations in $\bar{u}$ [see also Scott et al., 2008, Figure 10]. A similar argument can be made for cyclonic eddies. More generally, a field of mesoscale eddies with propagation direction deviant from westward might produce quasi-zonal patterns.

[7] Figure $1 \mathrm{~b}$ illustrates $\bar{u}$ estimated from 4 years of simulated SSH due to eddies. In this example, the eddies are not random as in the simulations of Schlax and Chelton [2008] but instead have position, amplitude, scale, and lifetime specified by a tracked-eddy database [Chelton et al., 2011a, hereafter, CSS2011]. One notes the existence of striations in eddy-generated $\bar{u}$ that are similar in appearance to observed striations (Figure 1a).

[8] Such arguments leave inconclusive the presence of zonal jets in the ocean. Given the importance of MZJs to an understanding of the general circulation of the ocean and potential support for geostrophic turbulence theory [Rhines, 1975; Baldwin et al., 2007] and/or jet formation by secondary instability mechanisms [Pedlosky, 1975; Berloff et al., 2009], we seek to quantify what portion of the striation signal is due to propagating eddies [Schlax and Chelton, 2008] and what portion remains unexplained.

\subsection{Focus of the Study}

[9] The focus of the present study is on striations in the subtropical South Pacific Ocean $\left(20^{\circ} \mathrm{S}-50^{\circ} \mathrm{S}, 200^{\circ} \mathrm{E}-280^{\circ} \mathrm{E}\right.$; black box in Figure 1). The region is sufficiently distant from equatorial and coastal regions and does not enclose strong current systems such as the Gulf Stream, Kuroshio, and Antarctic Circumpolar Current where a host of dynamical processes complicate interpretation of the data. For this reason, excluding differences in bathymetry, processes governing striations in the South Pacific should be representative of those in most midlatitude, open-ocean basins.

[10] In the present study, we examine striations in timeaveraged absolute dynamic topography (ADT). The motivation for use of ADT in the examination of striations is that it provides a dynamical quantity from which to appropriately isolate and identify eddies. In addition and in contrast with
SLA measurements, ADT contains stationary signals that may include zonal jets. Lastly, we mention that, to the extent that mesoscale eddies explain a portion of the striation signal in this data set, these results may shed light on the zonal patterns in other data sets. For example, at the end of this study we suggest eddies may be responsible for some portion of the banded structure observed in SST.

[11] This study is divided into three parts. In section 2, we describe methods employed in the study, including isolating eddy signatures and quantifying that portion of the striation signal attributed to eddies. Section 3 summarizes the results and is followed by a discussion in section 4 .

\section{Methods}

[12] Following Roemmich and Gilson [2001], we use the term "eddy" to refer to propagating anomalies seen in the altimeter record (and described by Chelton and Schlax [1996], Chelton et al. [2007], and CCS2011). That is, we do not distinguish between linear planetary waves (i.e., Rossby waves) and nonlinear coherent vortices in the surface ocean. We recognize that this distinction is important for understanding the dynamics associated with striations - are eddies embedded in MZJS and therefore derive energy from or feedback energy to the mean flow [Kamenkovich et al., 2009]? — but argue that it is not essential for kinematically distinguishing between jets and coherent, propagating anomalies.

\subsection{Data Description}

[13] The data used in this study are altimeter-derived measurements of SSH and a database of tracked eddies. SSH data consist of AVISO/CLS delayed-time, merged ADT, interpolated by SSALTO/DUACS onto a quarter-degree grid [Ducet et al., 2000; Le Traon et al., 2003], separated in duration by 7 days, and referred to as the reference series. (Data set acronyms are expanded in the Acknowledgments section.) These data span the time period October 1992 to July 2011, although analysis in this study is limited to data between October 1992 and December 2008. The database of tracked eddies, which is described by CCS2011 and generated by D. Chelton and M. Schlax, is available for the aforementioned time period. The eddy data set used in this study consists of locations, amplitudes, scales, azimuthal speeds, and lifetimes of tracked eddies having lifetimes $\geq 4$ weeks. One will note that the analysis presented in CCS2011 pertains to eddies with lifetimes

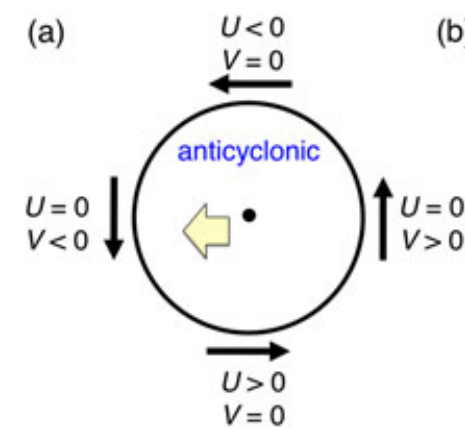

(b)

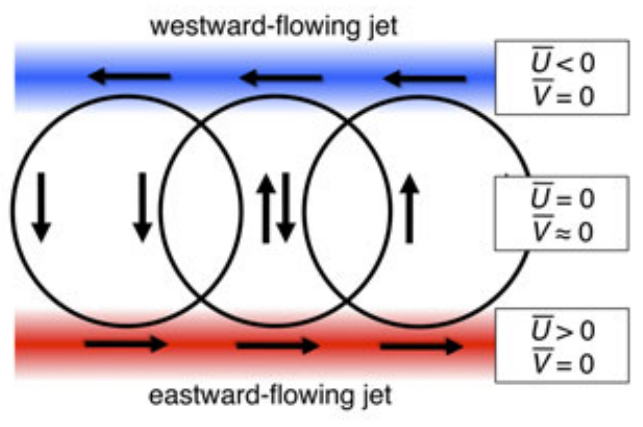

Figure 2. (a) A westward-propagating, anticyclonic eddy in the Southern Hemisphere has zonal and meridional velocities $u$ and $v$ along the perimeter of the eddy as shown. (b) Because velocity fields are averaged in time, $\bar{u}$ has small but finite amplitude while $\bar{v}$ approaches zero. The effect of the eddy is to create striations in $\bar{u}$. Illustration after Scott et al. [2008]. 
$\geq 16$ weeks. In spite of this discrepancy, we refer to CCS2011 when speaking of the eddy data set.

[14] The SSH product known as the "reference" series is used instead of the "updated" series - the reference series consists of data from two altimeters at any given time while the updated series consists of data from up to four altimeters - because the eddy database of CCS2011 was developed from the reference series and we wish for a close correspondence between ADT fields and the eddy database.

[15] The AVISO/CLS ADT data described above are the sum of altimeter-only measurements in the form of SLA and a 1992-2008 estimate of MDT [Rio et al., 2011]. The MDT field, referred to as combined mean dynamic topography (CMDT), is estimated using several data sets, including velocity estimates from drogued drifting buoys, hydrological profiles from conductivity-temperature-depth casts, and Argo profiling floats and wind stress reanalysis to remove Ekman effects. The MDT field also makes use of a geoid model (EIGEN-GRGS.RL02) and an altimeter-derived mean sea surface product (CLS01).

\subsubsection{Comment on Spatial Resolution of ADT}

[16] CCS2011 (section A.3) provide a thorough summary of the resolution characteristics of SLA based on meridional and zonal spectra. Because snapshots of ADT are heavily determined by SLA, conclusions reached by CCS2011 apply to our data set, as well. We summarize these below.

[17] CCS2011 found that (1) filtering characteristics of the optimal interpolation scheme appear to be approximately isotropic when expressed in degrees of latitude and longitude, (2) filter attenuation can be defined as monotonically increasing with decreasing wavelength (increasing wavenumber), and (3) attenuation of the signal at $2^{\circ}$ and $3^{\circ}$ is 0.5 and 0.0 , respectively. Signals having wavelengths of $2-3^{\circ}$ are therefore captured in a qualitative way. Recognizing that the spectral representation of an eddy covers a large range of wavelengths with most of the energy located at lower wavenumbers, the authors estimate the minimum eddy size that such filtering characteristics will permit. They estimate that Gaussian eddies with $e$-folding scale-which is a form of eddy radius - less than $0.4^{\circ}$ are significantly attenuated, those with scale $0.4^{\circ}-0.6^{\circ}$ are somewhat attenuated and those with scale greater than $0.6^{\circ}$ are completely resolved. At midlatitudes, these scales correspond roughly to 40 and $60 \mathrm{~km}$. Therefore, $60 \mathrm{~km}$ represents the minimum resolvable eddy scale for our data set.

\subsection{Processing Steps}

\subsubsection{Time-Averaging and Spatial Filtering}

[18] One of the processing steps commonly used to observe striations is time-averaging. The argument made for the use of a time average is that the desired signal is so small in amplitude that it is easily masked in individual snapshots of the ocean. The averaging period used in this study is 4 years, and therefore allows us to describe stationary striations. It also affords us the ability to break the 16-year record examined in this study into four distinct time intervals.

[19] In addition to time-averaging, it is common to apply a spatial high-pass filter to the time-averaged field in order to remove spatial trends irrelevant to the processes under examination [e.g., Maximenko et al., 2008; van Sebille et al., 2011]. Given the desire to replicate processing steps leading to striations documented elsewhere, mean ADT is spatially high-pass-filtered in a manner identical to that described by Maximenko et al. [2008]. This filtering process consists of several steps. First, a spatial low-pass filter is applied to the time-averaged field in order to isolate low wavenumber signals. We refer to this field as $L P 1$. The filter is a two-dimensional, approximately isotropic Hanning window with $4.0^{\circ}$ half-width. The result of this step is then subtracted from the original field, resulting in a high-pass-filtered field. This field is then filtered with the same Hanning window, isolating low-frequency content missed in the first step. We refer to this field as $L P 2$. Finally, the sum $(L P 1+L P 2)$ is subtracted from the original field, resulting in a spatially high-pass-filtered field. The effective magnitude response of this filtering process is shown in Figure 3.

[20] Filtering the time-averaged field in the above manner is equivalent to time-averaging spatially high-pass-filtered fields. This results from the linearity of both the averaging and high-pass-filtering processes. A second but equally important point is that the gradient of a time-averaged field is equal to the time-average of the gradient of underlying fields. In particular, $\bar{u}$ estimated from time-averaged ADT is equal to the time-average of $u$-fields.

\subsubsection{Identification and Removal of Eddy Signatures}

[21] The general assumption in this study is that one can decompose the observed velocity signal into that due to eddies and that due to other processes, which may include jets. The basis for this decomposition comes from the fact that for the large-scale $(>30 \mathrm{~km})$ ocean, the sum of forces acting on a parcel of fluid in the horizontal can be written as the sum of Coriolis and pressure forces [Wunsch and Stammer, 1998]. In combination with the hydrostatic relation, this geostrophic balance permits estimation of zonal and meridional components of surface velocity from dynamic height.

[22] An improved representation of upper ocean dynamics is the so-called gradient wind balance. This is a three-way balance of Coriolis, horizontal pressure gradient, and centripetal forces, where the latter term arises due to the curvature of parcel trajectories [Holton, 1979]. It can be shown that centripetal forces do not contribute significantly to the observed height signal. In particular, the magnitude of centripetal acceleration in the vicinity of eddies has been estimated at $1-3 \%$ that of the Coriolis acceleration. Given that eddies are the dominant signal in $\mathrm{SSH}$, and given that the centripetal term is larger than or equal to other nonlinear terms in the equations of motion, as well as viscous terms and time-tendency terms, we conclude that the geostrophic balance is a good approximation. (Assessing the validity of the geostrophic approximation requires a systematic scaling of the equations of motion. The importance of ageostrophic accelerations are determined by the Rossby $(R o)$ and Reynolds $(R e)$ numbers applicable to the flow. It can be shown that time-tendency, nonlinear advective, and viscous accelerations scale as $R o, R o$, and $R o / R e$ times the Coriolis acceleration, respectively. Because the Rossby number is small $\left(10^{-2}\right)$ and the Reynolds number large $\left(10-10^{5}\right)$, we find these accelerations are of order $10^{-2}, 10^{-2}$ and $10^{-3}$ to $10^{-5}$ times the Coriolis acceleration. [The latter range results from scaling the viscous acceleration term and noting that horizontal and vertical eddy viscosities have different magnitudes. We expect a significant departure from these scales in the Ekman layer where winds modify the balance through increased vertical shear-i.e., the $\partial / \partial z\left(v_{z} \partial u / \partial z\right)$ term.] In summary, the error made in making the geostrophic 


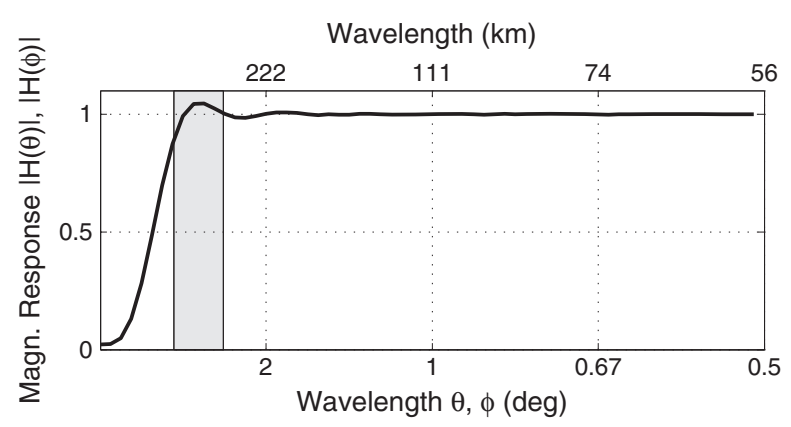

Figure 3. Effective magnitude response of the filtering process used in this study. The filter is nearly isotropic in latitude $\theta$ and longitude $\varphi$ in units of degree. Wavelengths in units of kilometers assume $1^{\circ}=111.2 \mathrm{~km}$ and, thus, correspond to meridional distances. The shaded box highlights wavelengths of $300-500 \mathrm{~km}$.

approximation is at most a few percent). Therefore, the ocean surface velocities are well approximated by

$$
\begin{gathered}
u=-\frac{g}{f} \frac{\partial \eta}{\partial y}=-\frac{g}{f}\left(\frac{\partial \eta_{\text {eddy }}}{\partial y}+\frac{\partial \eta_{\text {other }}}{\partial y}\right)=u_{\text {eddy }}+u_{\text {other }} \\
v=\frac{g}{f} \frac{\partial \eta}{\partial x}=\frac{g}{f}\left(\frac{\partial \eta_{\text {eddy }}}{\partial x}+\frac{\partial \eta_{\text {other }}}{\partial x}\right)=v_{\text {eddy }}+v_{\text {other }}
\end{gathered}
$$

where $x$ and $y$ are eastward and northward distances, respectively, $g$ is the acceleration due to gravity, $f$ is the Coriolis parameter, $\eta$ is the absolute dynamic height, and $u$ and $v$ are zonal and meridional velocities, respectively. Here, we have used the substitution $\eta=\eta_{\text {eddy }}+\eta_{\text {other }}$ and, owing to the linearity of the equations, defined zonal geostrophic velocities due to eddies and other processes. In this study, we are interested in $\bar{u}$ because $\bar{v}$ approaches zero.

[23] To determine if eddies give rise to striations in $\bar{u}$, it is necessary to identify eddies, isolate their ADT signature, and quantify their contribution to the time-averaged field. One manner of determining the overall contribution of eddies to $\bar{u}$ is to simulate a set of Gaussian eddies with amplitudes, scales, and lifetimes identical to those observed, compute a time-average of these fields and compare observed and simulated $\bar{u}$. This has been done and results in $\bar{u}$ estimated from Gaussian eddies having striations with similar appearance but smaller amplitude when compared with observed striations (Figure 1b). Eddies of parabolic shape [CCS2011] yield improved but comparable results (not shown). The discrepancy in the magnitude of striations, coupled with an imperfect alignment of striations when using eddies of a prescribed shape motivates use of an automated algorithm to identify and subtract eddies from individual ADT fields. This process is described below. We note that Chelton and Schlax offered to provide contours of eddies identified in their 2011 study. However, differences in the underlying data set (SLA vs. ADT) and the spatial filtering applied to SLA fields prior to identifying eddies has led us to develop our own contour-identification algorithm but one that closely follows that described by CCS2011 (Appendix B.2).

\subsubsection{Algorithm Description}

[24] The algorithm used in this paper searches for closed contours at various height levels, starting at $-100 \mathrm{~cm}$ and increasing in intervals of $0.25 \mathrm{~cm}$ in its search for anticyclonic eddies while starting at $+100 \mathrm{~cm}$ and decreasing in intervals of $0.25 \mathrm{~cm}$ in its search for cyclonic eddies. Because height contours are coincident with streamlines of geostrophic flow, one might also interpret the eddies identified from this algorithm as "closed circulation cells."

[25] In identifying closed contours from the combination of the ADT record and eddy centers in the eddy database, we require that Chelton-Schlax eddy centers be located within the closed contour, or perimeter, of the eddy identified with our algorithm. In addition, we allow closed regions of the eddy to include pixels out to a distance $2 L$ from the eddy center, where $L$ is the "radius of the circle that has the same area as the region within the closed contour of SSH with maximum average speed" [CCS2011]. Additional constraints on the selection of eddies are as follows: (1) eddy pixels (i.e., those pixels found within eddy perimeters) cannot be more than a distance $D$ from one another, where $D$ varies linearly between approximately $670 \mathrm{~km}$ at $20^{\circ} \mathrm{S}$ and $400 \mathrm{~km}$ at $30^{\circ} \mathrm{S}$, and is $400 \mathrm{~km}$ for latitudes poleward of $30^{\circ} \mathrm{S}$; (2) eddy pixels must not be assigned to more than one eddy; (3) an object identified as an eddy must contain at least 8 but no more than 1000 eddy pixels; and (4) the closed contour of the object must include an extrema with sign determined by the polarity of the eddy in the eddy database. The extrema need not be the eddy center specified in the eddy database. Figure 4a illustrates the identification of eddy contours in ADT.

[26] Having identified the perimeters of eddies, one proceeds to remove eddies from ADT fields in order to determine the role eddies play in creating striations. The removal of eddies from ADT was accomplished in the following

(a)

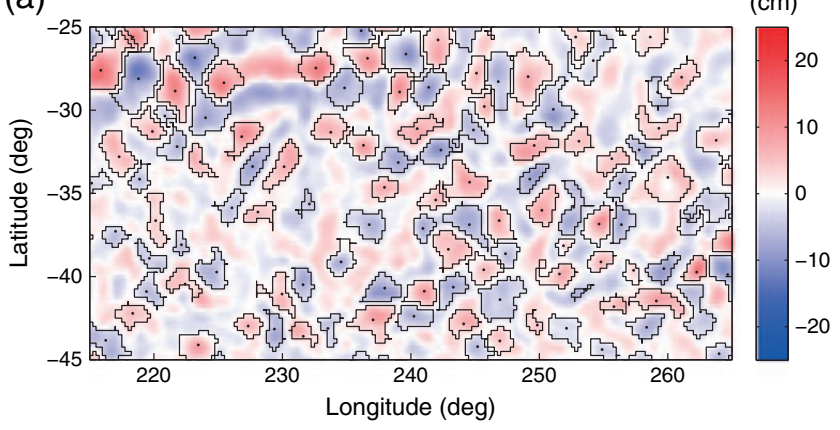
$(\mathrm{cm})$

(b)

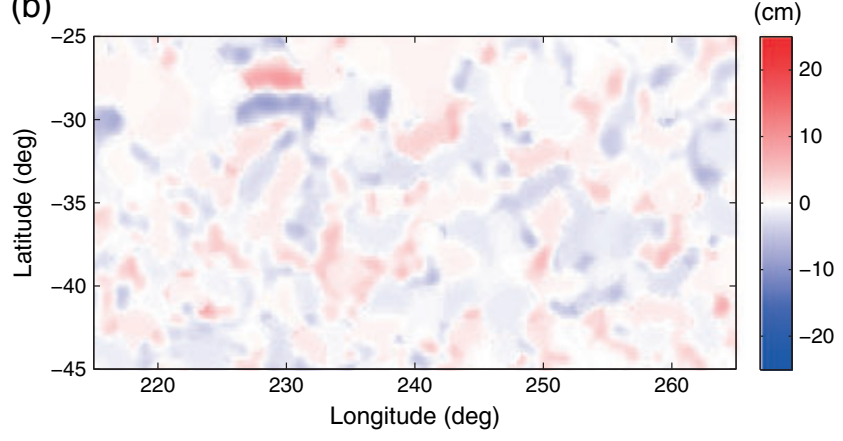

Figure 4. Illustration of (a) the contour-identification and (b) eddy removal algorithm applied to filtered ADT in the South Pacific, valid 6 January 1993. Black dots denote eddy centers obtained from the eddy database. 
manner. ADT values within eddy perimeters were replaced with those of a smoothed interpolated field. The smoothed interpolated field was generated by (1) assigning to eddy pixels within each eddy the value of the threshold used to obtain a closed contour and (2) spatially low-pass-filtering this field with a $9 \times 9$ pixel $\left(2.25^{\circ} \times 2.25^{\circ}\right)$ Gaussian window having approximately $1.9^{\circ}$ half-power width. The result of removing eddies and replacing them with pixels from the smoothed field is shown in Figure $4 \mathrm{~b}$.

[27] Finally, to estimate average zonal geostrophic velocity attributed to eddies, we computed the time-average of ADT with eddies removed and subtracted this from the total observed time-averaged ADT field. This results in an estimate of mean ADT due to eddies alone and from which we calculate $\bar{u}$ due to eddies. We use the terms $\bar{u}_{\text {total }}$ and $\bar{u}_{\text {eddy }}$ to denote total and eddy-only $\bar{u}$ fields, and $\bar{u}_{\text {diff }}=\bar{u}_{\text {total }}-$ $\bar{u}_{\text {eddy }}$ to refer to the difference.

\subsubsection{Algorithm Characteristics}

[28] It is possible that zonally-elongated objects are frequently identified by the algorithm. This would reduce a considerable fraction of the striation signal while calling into question the eddy-nature of ADT anomalies identified here. From illustrations of eddy contours, this does not appear to be the case. For example, two pronounced anisotropic structures are visible in Figure $4 \mathrm{a}$ near $27^{\circ} \mathrm{S}-30^{\circ} \mathrm{S}, 225^{\circ} \mathrm{E}-232^{\circ} \mathrm{E}$. These positive and negative plume-like features are preserved by the contour identification and eddy-removal process (Figure $4 \mathrm{~b}$ ). While qualitative, this gives us some assurance the algorithm is properly distinguishing between jets and eddies. A more systematic assessment follows.

[29] To determine if features selected by the algorithm are anisotropic, on average, we examined the histogram of eddy perimeters and plotted these as a function of distance from the centroids of the objects. Figure 5 illustrates the histogram of eddy perimeters relative to the centroids of identified eddies, where zonal and meridional distances have been

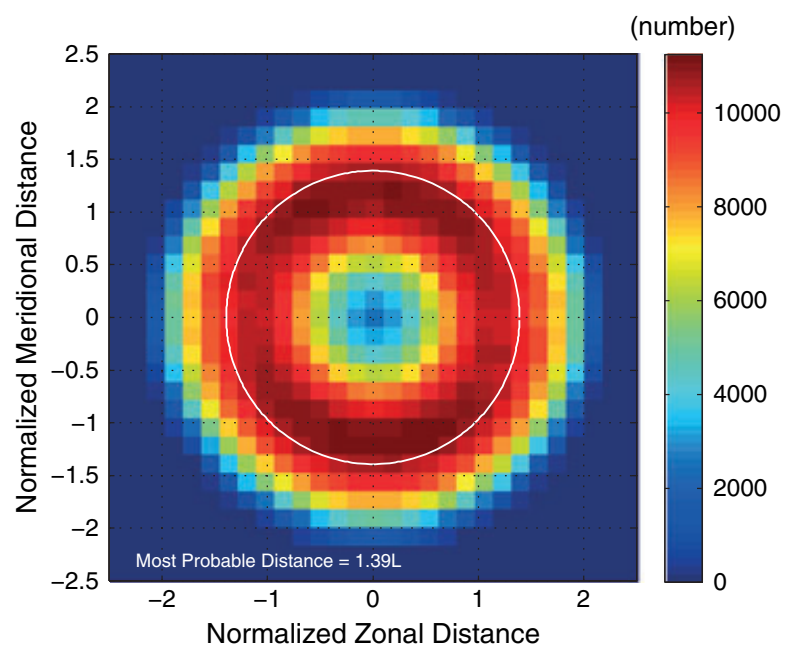

Figure 5. Histogram of eddy perimeter locations determined by the contour-identification algorithm. Eddy locations are shown as scaled distances from eddy centroids and distances are normalized by the horizontal eddy-scale $L$ as defined in the eddy database. normalized by the eddy scale $L$ obtained from the database. One notes two characteristics from this figure. The first is that the histogram of eddy perimeters reveals little or no anisotropy in the shapes of identified eddies. The second is that the most probable perimeter distance is approximately $1.4 \mathrm{~L}$, providing confidence that the threshold distance of $2 L$ (described above) is reasonable.

[30] Note that the perimeter distance is not the same as the eddy scale. The former describes the horizontal extent of the eddy signature in $\mathrm{SSH}$ while the latter describes the radius at which the rotational speed of the eddy is a maximum and has potential dynamical significance: fluid within this distance is trapped by the eddy if its circulation speed $U$ exceeds the propagation speed $c$ of the eddy [CCS2011].

[31] Some limitations should be noted regarding the contour-identification and eddy removal procedure. These include the following: (1) the set of eddies identified and tracked are restricted to those eddies having lifetimes greater than or equal to 4 weeks; (2) a small percentage $(1 \%)$ of eddies identified and tracked by Chelton and Schlax are not identified in the corresponding ADT fields either due to the fact that (i) the tracked eddies may not have a corresponding eddy signature in the altimeter record since CCS2011 allow for the reappearance of an eddy by looking ahead several time steps, or (ii) the latitude and longitudes of eddy tracks have been smoothed [CCS2011, section B.4 of ] to the extent that eddy centers no longer fall inside the perimeters of eddies identified here; (3) the contour-identification algorithm sometimes connects two visually distinct anomalies in spatially-filtered ADT fields; and (4) removal of eddies and the subsequent replacement of eddy pixels with values makes an assumption about the nature of the SSH field in the absence of eddies. Here, this assumption is that an ADT signature exists in the absence of an eddy. Despite these limitations, we believe this method to be useful in providing an estimate of the contribution of eddies to striations. We note that items (1), (2), and (4) underestimate dynamic height due to eddies, while item (3) has the potential of overestimating mean ADT due to eddies. In the Discussion section, we attempt to bound the energy due to eddies.

\subsection{Characterization and Comparison of $\overline{\boldsymbol{u}}_{\text {total }}$, $\overline{\boldsymbol{u}}_{\text {eddy }}$, and $\overline{\boldsymbol{u}}_{\text {diff }}$}

[32] In determining the contribution of eddies to striations in $\bar{u}$, we characterize and compare $\bar{u}_{\text {total }}, \bar{u}_{\text {eddy }}$, and $\bar{u}_{\text {diff. }}$ This is accomplished by computing variances and covariances of the fields. We compute the variances, $\sigma_{\bar{u}}^{2}$, in order to characterize their relative amplitudes and covariances to determine the degree of similarity amongst the fields. Here, $\sigma_{\bar{u}}$ represents a deviation from a spatial average and the averaging region is chosen to be the South Pacific.

[33] Note that variances of eddy-only and difference fields do not add to equal the total variance. This is seen in the expression for the variance of $\bar{u}$

$$
\sigma_{\bar{u}_{\text {total }}}^{2}=\sigma_{\bar{u}_{\text {eddy }}}^{2}+\sigma_{\bar{u}_{\text {diff }}}^{2}+2 \sigma_{\bar{u}_{\text {eddy }}}^{2} \bar{u}_{\text {diff }},
$$

where the last term is twice the covariance between eddyonly and difference fields. Normalizing this expression by the total variance yields an expression for the relative contributions of $\bar{u}_{\text {eddy }}, \bar{u}_{\text {diff }}$, and the covariance between the two 
fields. In particular, the fraction of variance explained by eddies is $\sigma_{\bar{u}_{\text {ddy }}}^{2} / \sigma_{\bar{u}_{\text {total }}}^{2}$. Both observed and fractional variances are reported in the next section.

[34] In addition to comparing relative magnitudes of $\bar{u}_{\text {total }}$, $\bar{u}_{\text {eddy }}$, and $\bar{u}_{\text {diff }}$, correlation coefficients are used to compare the similarity of fields. In terms of variances and covariances, the signed correlation coefficient is defined as [Bendat and Piersol, 2000]

$$
\rho_{i, j}=\frac{\sigma_{\bar{u}_{i} \bar{u}_{j}}^{2}}{\sigma_{\bar{u}_{i}} \sigma_{\bar{u}_{j}}} .
$$

Here, $i$ and $j$, where $i \neq j$, are subscripts used to denote total, eddy-only, or difference fields. A correlation coefficient close to +1.0 suggests the two fields are linearly related through a positive scale factor, while a negative value demonstrates that $\bar{u}$ fields have features common to both but opposite in sign; a value near zero demonstrates littleto-no linear relationship between the fields.

[35] When computing the above quantities, it is helpful to subsample $\bar{u}_{\text {total }}, \bar{u}_{\text {eddy }}$, and $\bar{u}_{\text {diff }}$ in an effort to obtain decorrelated samples. Given that deccorrelation scales within optimally interpolated fields are $100-300 \mathrm{~km}$ - although this varies with latitude [CCS2011, Appendix A.2] — and recognizing that the signal of interest is zonally-elongated, fields were sampled every one degree in latitude and every three degrees in longitude.

\section{Results}

[36] This section examines the role eddies play in the generation of striation patterns. Given that eddies are found to account for a significant fraction of the signal present in $\bar{u}$, the hypotheses posed by Schlax and Chelton [2008] are tested, including (1) the decay of zonal standard deviation with averaging period and (2) the amplitudes and scales of eddies most responsible for striations. First, we examine zonal and meridional scales of striations to demonstrate that striations examined in this study are comparable to those in other studies.

\subsection{Zonal and Meridional Spectra of $\overline{\boldsymbol{u}}$}

[37] Figure 6 depicts zonal and meridional spectra of $\bar{u}$ as a function of averaging period. As the averaging period increases, the energy in the spectra appears to move from higher to lower zonal wavenumbers, consistent with the view that westward-propagating anomalies dominate the time-averaged field [Schlax and Chelton, 2008]. Meridional spectra reveal a different pattern. One notes that for all averaging periods, a large portion of energy is located within the $0.002-0.003 \mathrm{~km}^{-1}$ wavenumber band, corresponding to wavelengths of $330-500 \mathrm{~km}$. By $T=60$ weeks, the spectra reveal a single peak near $0.0025 \mathrm{~km}^{-1}(400 \mathrm{~km})$, a trend extending to larger averaging periods. The $\bar{u}$ fields examined in the remainder of the study are those having averaging periods of $\sim 200$ weeks (4 years) and therefore correspond to $\bar{u}$ containing large $(>1000 \mathrm{~km})$ zonal and $\sim 400 \mathrm{~km}$ meridional scales. These zonal and meridional scales show good agreement with those observed elsewhere [Maximenko et al., 2008; van Sebille et al., 2011].

\subsection{Comparison of $\overline{\boldsymbol{u}}_{\text {total }}, \overline{\boldsymbol{u}}_{\text {eddy }}$, and $\overline{\boldsymbol{u}}_{\text {diff }}$}

[38] Figure 7 illustrates $\bar{u}_{\text {total }}, \bar{u}_{\text {eddy }}$, and $\bar{u}_{\text {diff }}$ estimated from four 4-year averages of ADT in the South Pacific. Variances and covariances are shown in Table 1 and normalized variances and correlation coefficients are shown in Table 2. One observes a high degree of similarity between $\bar{u}_{\text {total }}$ and $\bar{u}_{\text {eddy }}$ : correlation coefficients between the two fields range from 0.90 to 0.93 . In addition, an appreciable fraction of variance is explained by eddies; values range from 0.46 to 0.57 . The difference, $\bar{u}_{\text {diff }}$, is smaller in amplitude but contains residual energy at locations similar to $\bar{u}_{\text {total }}$. This is reflected in moderate-to-high correlation coefficients between $\bar{u}_{\text {total }}$ and $\bar{u}_{\text {diff }}(0.77-0.80)$. The similarity of $\bar{u}_{\text {eddy }}$ and $\bar{u}_{\text {diff }}$ is not as high, with correlation coefficients range from 0.45 to 0.58 . Lastly, covariance estimates between eddy-only (a)

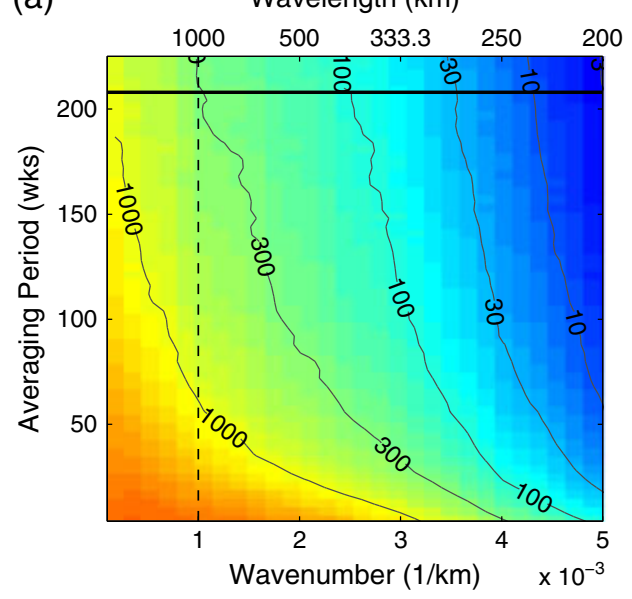

(b)

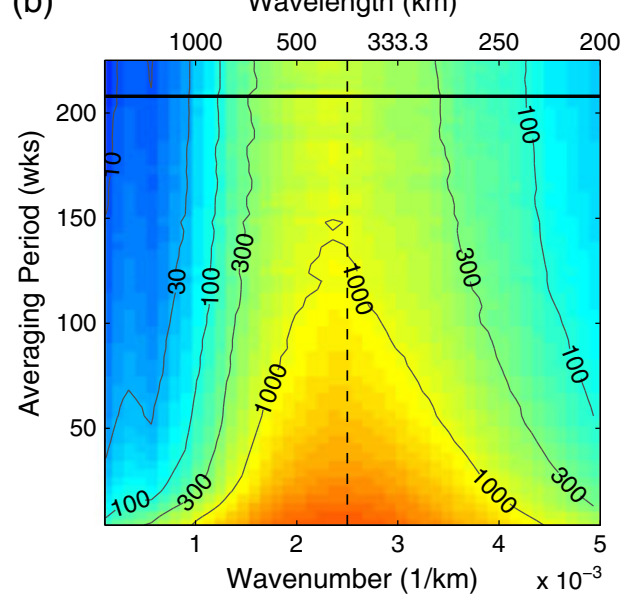

Figure 6. (a) Zonal and (b) meridional spectra of $\bar{u}$ in the South Pacific as a function of averaging period. Solid horizontal lines mark averaging periods of 4 years while vertical dashed lines highlight zonal and meridional wavelengths of 1000 and $400 \mathrm{~km}$, respectively. Spectra were created using all available data between 1 January 1993 and 31 December 2008. Individual 4-year averaging periods show similar structure. Note that spectral contours are illustrated on a logarithmic scale and units are $\mathrm{cm}^{2} \mathrm{~s}^{-2} \mathrm{~km}$. 

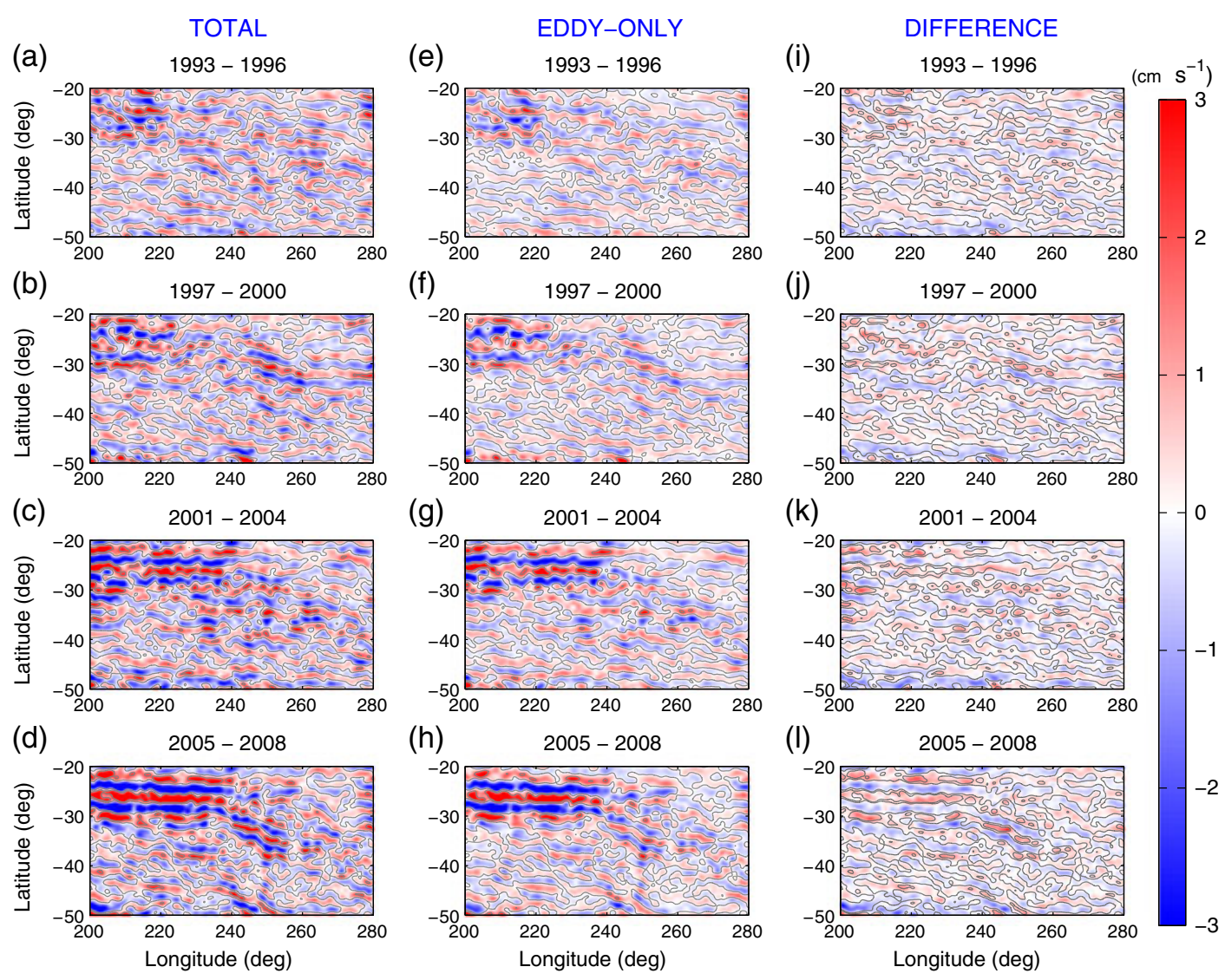

Figure 7. Comparison of (a-d) $\bar{u}_{\text {total }},(\mathrm{e}-\mathrm{h}) \bar{u}_{\text {eddy }}$, and (i-1) $\bar{u}_{\text {diff }}$ estimated from ADT during four 4 year averaging periods. Contour lines are shown every $2 \mathrm{~cm} \mathrm{~s}^{-1}$ and contours in difference Figures $7 \mathrm{i}-71$ correspond to those of $\bar{u}_{\text {total }}$.

Table 1. Variances and Covariances of $\bar{u}_{\text {total }}, \bar{u}_{\text {eddy }}$, and $\bar{u}_{\text {diff }}{ }^{\mathrm{a}}$

\begin{tabular}{lllllll}
\hline Averaging Period & $\sigma_{\bar{u}_{\text {total }}}^{2}$ & $\sigma_{\bar{u}_{\text {cddy }}}^{2}$ & $\sigma_{\bar{u}_{\text {diff }}}^{2}$ & $\sigma_{\bar{u}_{\text {total }} \bar{u}_{\text {cddy }}}^{2}$ & $\sigma_{\bar{u}_{\text {total }}}^{2} \bar{u}_{\text {diff }}$ & $\sigma_{\bar{u}_{\text {cddy }} \bar{u}_{\text {diff }}}^{2}$ \\
\hline $1993-1996$ & 0.758 & 0.351 & 0.170 & 0.470 & 0.288 & 0.119 \\
$1997-2000$ & 0.972 & 0.506 & 0.187 & 0.646 & 0.326 & 0.139 \\
$2001-2004$ & 1.707 & 0.934 & 0.233 & 1.204 & 0.503 & 0.270 \\
$2005-2008$ & 2.286 & 1.301 & 0.283 & 1.652 & 0.634 & 0.351 \\
\hline
\end{tabular}

${ }^{\mathrm{a}}$ Units are $\mathrm{cm}^{2} \mathrm{~s}^{-2}$.

and difference fields account for $0.29-0.32$ times the total variance (column 4 in Table 2), leaving a small fraction attributed to the difference $(0.12-0.22)$.

\subsection{Decay of $\sigma_{\bar{u}}$ With Averaging Period}

[39] Schlax and Chelton [2008] derive an expression for the variance of $\bar{u}$ due to eddies as a function of averaging period $T$. In this expression, the amplitudes and scales of eddies determine to a large extent the velocity variance, with the square-root of this quantity falling off as $1 / T$. To determine whether the standard deviation $\sigma_{\bar{u}}$ decays as $1 / T$, we examined the $\mathrm{SSH}$ record as a function of averaging period, computed $\sigma_{\bar{u}}$ for each averaging period and applied a leastsquares regression to the data. Here, we computed $\bar{u}$ from time-averaged ADT as a function of averaging period, increasing in 4 week intervals from 4 to 200 weeks ( $\sim 4$ years). We did this for both $\bar{u}_{\text {total }}$ and $\bar{u}_{\text {eddy }}$.

Table 2. Fractional Variances and Correlation Coefficients Between $\bar{u}_{\text {total }}, \bar{u}_{\text {eddy }}$, and $\bar{u}_{\text {diff }}{ }^{\text {a }}$

\begin{tabular}{|c|c|c|c|c|c|c|}
\hline Averaging Period & $\sigma_{\bar{u}_{\text {eddy }}}^{2} / \sigma_{\bar{u}_{\text {total }}}^{2}$ & $\sigma_{\bar{u}_{\text {diff }}}^{2} / \sigma_{\bar{u}_{\text {total }}}^{2}$ & $2 \sigma_{\bar{u}_{\text {eddy }}^{2}}^{2} \bar{u}_{\text {diff }} / \sigma_{\bar{u}_{\text {total }}^{2}}^{2}$ & $\rho_{\text {total,eddy }}$ & $\rho_{\text {total,diff }}$ & $\rho_{\text {eddy,diff }}$ \\
\hline 1993-1996 & 0.46 & 0.22 & 0.32 & 0.91 & 0.80 & 0.49 \\
\hline $1997-2000$ & 0.52 & 0.19 & 0.29 & 0.92 & 0.77 & 0.45 \\
\hline 2001-2004 & 0.55 & 0.14 & 0.31 & 0.95 & 0.80 & 0.58 \\
\hline 2005-2008 & 0.57 & 0.12 & 0.31 & 0.96 & 0.79 & 0.58 \\
\hline $1993-1996$ * & 0.41 & 0.23 & 0.36 & 0.92 & 0.85 & 0.58 \\
\hline $1997-2000^{*}$ & 0.49 & 0.23 & 0.28 & 0.90 & 0.76 & 0.40 \\
\hline $2001-2004^{*}$ & 0.58 & 0.19 & 0.23 & 0.91 & 0.70 & 0.35 \\
\hline $2005-2008^{*}$ & 0.61 & 0.15 & 0.24 & 0.93 & 0.69 & 0.38 \\
\hline
\end{tabular}

${ }^{\text {a } R e s u l t s ~ o f ~ a p p l y i n g ~ t h e ~ c o n t o u r-i d e n t i f i c a t i o n / r e m o v a l ~ a l g o r i t h m ~ t o ~ S L A ~(r e f e r e n c e d ~ t o ~ a n ~ O c t o b e r ~} 1992$ to December 2008 mean) are highlighted by asterisks. 
(a)

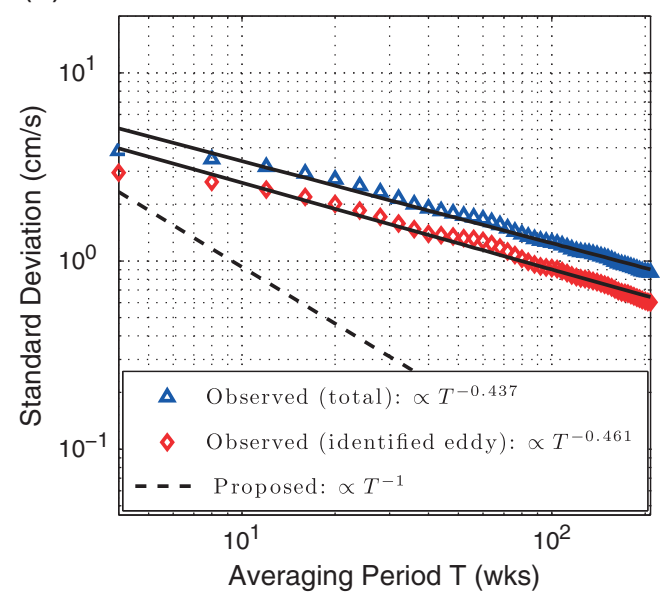

(b)

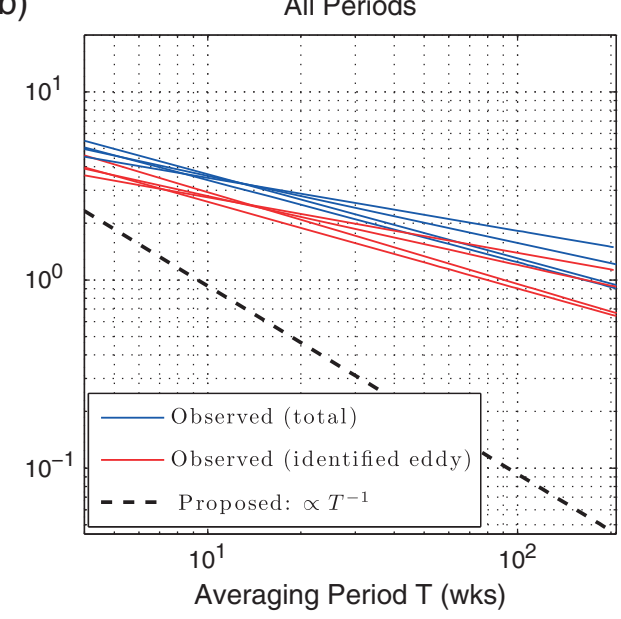

Figure 8. (a) Standard deviation of $\bar{u}_{\text {total }}$ and $\bar{u}_{\text {eddy }}$ as functions of averaging period, beginning January 1993, increasing in 4-week intervals and ending December 1996. Solid line: least-squares fit, $y=\alpha T^{\beta}$ with $\alpha=9.301$ and $\beta=-0.437$. Dashed line: $y=\alpha T^{\beta}$ with $\alpha=9.301$ and $\beta=-1$ as proposed by a model of randomly-positioned eddies. (b) Same as for Figure 8a but for all time periods and only showing least-squares fits and proposed falloffs. Regression coefficients are listed in Table 3.

[40] It is worth noting that the expression derived by Schlax and Chelton [2008] is an expected value computed at a given point. In the present case, we have defined $\sigma_{\bar{u}}$ with respect to a spatial mean and it is therefore descriptive of the South Pacific region as a whole. The comparison between the two forms of $\sigma_{\bar{u}}$ is valid so long as samples within the region are selected from the same distribution as samples at any given location.

[41] Figure 8 shows the standard deviation of zonal geostrophic velocity $\sigma_{\bar{u}}$ as a function of averaging period $T$ starting January 1993, increasing in 4-week intervals and ending December 1996. Note that the data are well-approximated by an equation of the form of $y=\alpha T^{\beta}$ where $\alpha=9.301$ and $\beta=-0.437$. This is compared with a $1 / T$ falloff suggested by Schlax and Chelton [2008]. In addition to values for the 1993-1996 time period, values of $\alpha$ and $\beta$ for the other time periods are shown in Table 3. In all cases, the data follow a trend distinctly different from $1 / T$, with values of $\beta$ ranging between -0.282 and -0.447 . This suggests processes giving rise to striations are not explained by randomly positioned eddies, alone.

\subsection{Class of Eddies Most Responsible for Striations}

[42] An additional hypothesis posed by Schlax and Chelton [2008] concerning eddies and striations is that eddies of large amplitude and scale are most responsible for the observed

Table 3. Parameters $\alpha$ and $\beta$ Obtained From Least-Squares Fits of $\sigma_{\bar{u}_{\text {total }}}$ and $\sigma_{\bar{u}_{\text {eddy }}}$ During Four Time Periods ${ }^{\mathrm{a}}$

\begin{tabular}{lrccc}
\hline Time Period & $\alpha$ (total) & $\beta$ (total) & $\alpha$ (eddy) & $\beta$ (eddy) \\
\hline $1993-1996$ & 9.301 & -0.437 & 7.530 & -0.461 \\
$1997-2000$ & 10.216 & -0.447 & 9.022 & -0.488 \\
$2001-2004$ & 8.144 & -0.357 & 6.490 & -0.366 \\
$2005-2008$ & 6.695 & -0.282 & 5.427 & -0.295 \\
\hline
\end{tabular}

${ }^{\mathrm{a}}$ The fit has the form $y=\alpha T^{\beta}$, where $T$ is the averaging period in weeks. Units of $\alpha$ are $\mathrm{cm} \mathrm{s}^{-1} \mathrm{wks}^{-\beta}$. patterns and that these eddies are few. Recall that each eddy identified in this study can be cross-referenced to the set of eddies identified by CCS2011 and are therefore associated with a given amplitude, scale, lifetime, etc. One can therefore test this hypothesis by creating $\bar{u}$-fields attributed to eddies of each amplitude and scale and examine $\bar{u}_{\text {total }}, \bar{u}_{\text {eddy }}$, and $\bar{u}_{\text {diff }}$ for all amplitudes and scales. In particular, eddies of a particular class contribute most to the observed striations if the variance of $\bar{u}_{\text {diff }}$ is minimized. (Strictly speaking, eddies of a certain class contribute most to the observed striations if the meansquared value of $\bar{u}_{\text {diff }}$ is minimized. However, the mean of $\bar{u}_{\text {diff }}$ is so close to zero that one can achieve the same effect by simply minimizing the variance.)

[43] Figure 9 depicts the fraction of total variance contained in $\bar{u}_{\text {diff }}$ (i.e., $\sigma_{\bar{u}_{\text {diff }}}^{2} / \sigma_{\bar{u}_{\text {total }}}^{2}$ ) as a function of eddy amplitude and scale. In addition, it illustrates the correlation coefficient between $\bar{u}_{\text {total }}$ and $\bar{u}_{\text {eddy }}$ as a function of eddy amplitude and scale. While some variation exists for different averaging periods, the mean describes the trends in $\sigma_{\bar{u}_{\text {diff }}}^{2} / \sigma_{\bar{u}_{\text {total }}}^{2}$ well. One notes that the fractional variance is minimized by eddies of small-to-medium amplitude $(1-9 \mathrm{~cm})$ and medium-to-large scale $(50-150 \mathrm{~km})$. This trend is reflected among correlation coefficients, as well, where $\bar{u}_{\text {eddy }}$ due to eddies of these amplitudes and scales are most correlated with $\bar{u}_{\text {total }}$. Ranges of amplitudes and scales are defined as the amplitudes and scales for which the mean in fractional variance is less than 0.95 and the mean in correlation exceeds 0.4 (horizontal lines in Figure 9).

[44] It is important to note that eddy amplitudes may be biased low due to the existence of spatial gradients in SLA fields whose horizontal scale exceeds that of the eddy, thereby hindering identification of eddy contours [CCS2011]. CCS2011 apply a two-dimensional high-pass filter prior to estimating eddy amplitudes in an effort to remove such bias. However, because filter dimensions are large $\left(10^{\circ}\right.$ and $20^{\circ}$ half-widths in latitude and longitude, respectively) eddy bias remains. It is also possible that bias in eddy amplitudes enters 

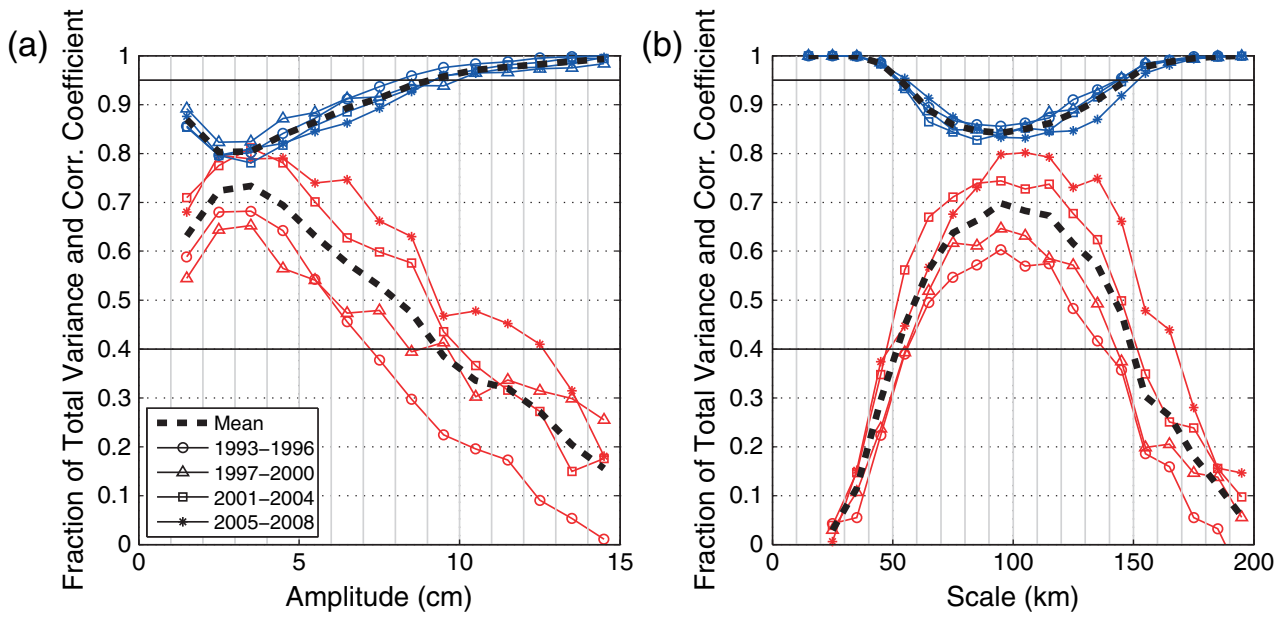

Figure 9. Fraction of total variance contained in $\bar{u}_{\text {diff }}$ (blue, top) and correlation coefficients between $\bar{u}_{\text {total }}$ and $\bar{u}_{\text {eddy }}$ (red, bottom) as a function of eddy (a) amplitude and (b) scale. Thin lines illustrate values for each averaging period and thick, dashed lines illustrate the means. Bin widths are $1 \mathrm{~cm}$ and $10 \mathrm{~km}$ for eddy amplitude and scale, respectively.

as a result of identifying eddies in SLA referenced to 19931999 rather than ADT or SLA referenced to a longer-duration period; however, we have determined this to be insignificant $(<0.3 \mathrm{~cm})$ for our application.

[45] To obtain a more accurate picture of the amplitudes of eddies giving rise to striation patterns, a set of revised eddy amplitudes were obtained from the spatially high-passfiltered fields used in our study. Given that the filter used in our study has half-width equal to $4^{\circ}$, large-scale gradients are attenuated. Eddy amplitudes were obtained in the following manner. Amplitudes of anticyclonic (cyclonic) eddies were estimated by taking the magnitude of the difference between the maximum (minimum) $\mathrm{SSH}$ value within the eddy and the average height along the perimeter of the eddy identified during the contour-identification step. In this respect, the estimation of eddy amplitudes is the same as that described by CCS2011.

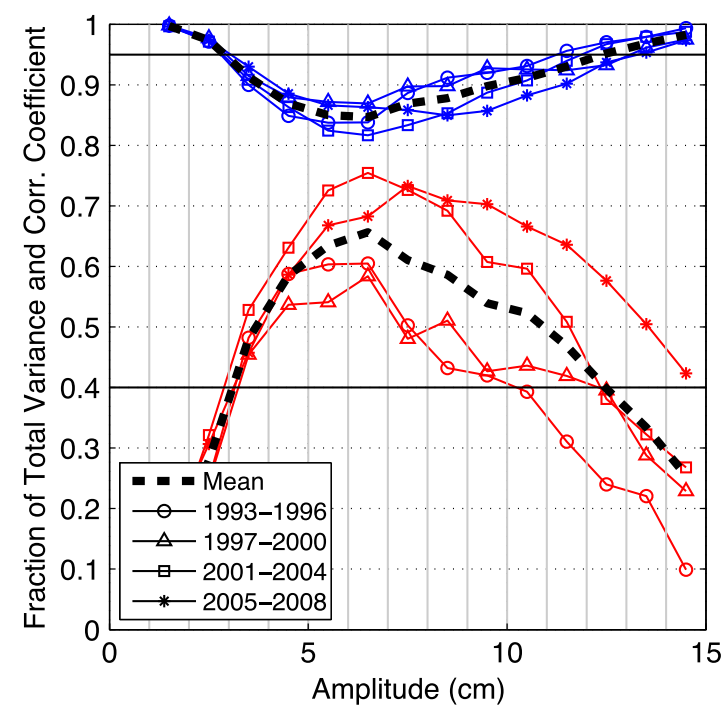

Figure 10. Fraction of total variance contained in $\bar{u}_{\text {diff }}$ (blue, top) and correlation coefficients between $\bar{u}_{\text {total }}$ and $\bar{u}_{\text {eddy }}$ (red, bottom) as a function of revised eddy amplitude.
[46] The fraction of total variance contained in $\bar{u}_{\text {diff }}$ and correlation coefficients based on revised eddy amplitudes are shown in Figure 10. Note that the trough (peak) in fractional variance (correlation) shifts from eddies of low amplitude to those of moderate amplitude $(3-12 \mathrm{~cm})$, where again the range of amplitudes is defined by those amplitudes for which the mean falls below 0.95 (exceeds 0.4 ). This adjusts earlier estimates and suggests that eddies of moderate amplitude and scale contribute most to the observed patterns.

[47] While these results define the type of eddy most responsible for the observed striations, they do not tell us the number of eddies falling into this category relative to the total number of eddies observed. Figure 11 illustrates the histogram of eddies in the South Pacific as a function of revised eddy amplitude and scale. This can be compared

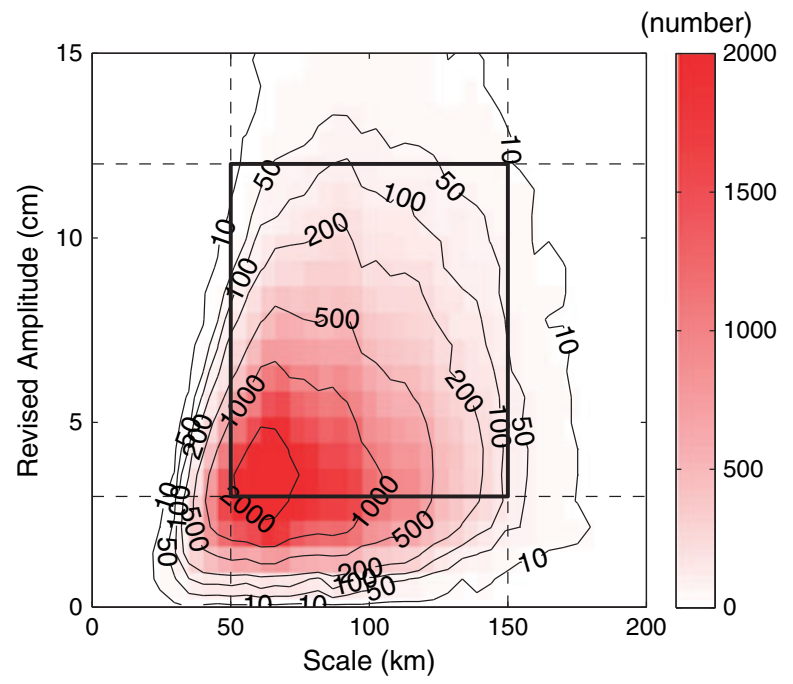

Figure 11. Histogram of eddies in the South Pacific (1992-2008) as a function of revised amplitude and scale. The black box highlights the intersection of amplitudes and scales most correlated with observed striations. 
with Figure 9c of CCS2011 for the global ocean and for their eddy amplitudes. The percentage of observations falling into the intersection of the two classes described above (i.e., $3-12 \mathrm{~cm}$ and $50-150 \mathrm{~km}$ ) is approximately $75 \%$, an appreciable percentage of the total number of observations $(227,000)$. (Note that the scale and amplitude of an eddy may change over its lifetime.) From this, we conclude that striations are not the result of a small number of largeamplitude and large-scale eddies but rather a significant number of eddies with a broad range of amplitudes and scales.

\section{Conclusions and Discussion}

[48] Two conclusions emerge from this study: (1) eddies contribute significantly to the observed striations and (2) the model of random eddies proposed by Schlax and Chelton [2008] does not appear to be correct. We found that a large number of moderate-amplitude $(3-12 \mathrm{~cm})$ and moderate-scale $(50-150 \mathrm{~km})$ eddies contribute significantly to the observed striations and the standard deviation of $\bar{u}$ decays with averaging period with a rate different from the inverse relationship proposed by Schlax and Chelton [2008].

\subsection{Limitations}

[49] This study has focused on striations in the subtropical South Pacific Ocean. Such a focus naturally restricts conclusions and prevents extrapolation to other regions of the world. However, we argue that to the extent that dynamics in the South Pacific are similar to those in other midlatitude, openocean basins, results should extend to these regions, as well.

\subsubsection{Errors in the Altimeter Product}

[50] Measurement and systematic errors of altimeter data include sensor noise, atmospheric errors, sea state biases, orbit errors, and errors in the removal of inverse barometer and tidal signals [Martin, 2004]. While collectively these errors can exceed several centimeters, they are estimated to be $2 \mathrm{~cm}$ when averaged over time and spatial scales similar to those examined in this study [Cheney et al., 1994]. In addition to measurement and systematic errors, the altimeter data used in this study suffer from errors resulting from interpolation of data between tracks. Recall that the data used in this study and referred to as the reference series consist of optimally interpolated measurements from two altimeters. Because the separation between altimeter tracks can be large (e.g., 200-300 km for TOPEX/Poseidon and Jason1 tracks in our region [Chelton et al., 2001, Figure 61]), the error can be large. Thus, the reference series may not suitably resolve the ocean surface in some locations.

[51] One method of gaining insight into the magnitude of this error is to compare reference and updated products during a time when data from four satellite altimeters are available. Pascual et al. [2006] have done this and reported larger SSH anomalies and enhanced eddy kinetic energy when using the updated series. In addition, Beron-Vera et al. [2010] demonstrated qualitative differences between surface structures in reference and updated data (see, for example, their Figure 4), but ultimately concluded that mixing inferred from the two products is similar. Our own comparison during October 2002 to September 2005 (not shown) reveals that differences in $\mathrm{SSH}$ between the two products can be as large as $6 \mathrm{~cm}$ (RMS differences of $0.7 \mathrm{~cm}$ ). This provides a plausible mechanism by which SSH contours identified in this study (see section 2.2.2.1) might differ from those determined from the updated series, and hence the real ocean. We acknowledge this as a potential error.

\subsubsection{Errors in Mean Dynamic Topography}

[52] Another potential limitation is the use of MDT. We feel this is a limitation because, in addition to errors in the optimally interpolated altimeter fields in the form of SLA, the MDT product used in the study [Rio et al., 2011] (i.e., CMDT) may contain errors. For example, it is possible that wind stress reanalyses contain errors that then propagate to MDT during the calculation of Ekman effects. In addition, it is notable that the spatial distribution of hydrological profiles from Argo floats (2002-2008) is substantially greater than those from CTD casts (1993-2008) [Rio et al., 2011, Figure 2]. We mention this because it is possible the mesoscale signal in CMDT is more representative of the latter-half of the averaging period than the entire 1992-2008 period. Ideally, dynamic height could be estimated by subtracting a high-resolution geoid from altimeter measurements, allowing an independent comparison of geoid and in situ based MDTs. However, geoid models with sufficient accuracy on the mesoscale do not presently exist. We expect such models will be available in the near future from, for example, data collected by the Gravity field and steady state Ocean Circulation Explorer satellite. Finally, we note that a parallel study using altimeter-only measurements (i.e., SLA referenced to a 16 year mean) has been conducted and yielded nearly identical results. These are shown in Table 2 and are denoted by asterisks. This may indicate that MDT contains both eddies and jet-like processes and that the relative ratio of these signals is similarly reflected in SLA.

[53] Recall that ageostrophic terms in the equations of motion have been neglected in this study. While the geostrophic approximation is accurate for individual snapshots of the upper ocean, it has yet to be determined whether ageostrophic terms are negligible when averaged for many years. In particular, deviations from geostrophy, such as those resulting from eddy-eddy or eddy-mean flow interactions, may accumulate in time. We have not estimated the magnitude nor the spatial distribution of these deviations relative to the observed striations.

\subsubsection{Algorithm Limitations}

[54] The most significant limitation of this study is the ability of the eddy identification and removal algorithm to correctly identify eddies. Our ability to separate eddies from the background mesoscale field is limited by two factors. First, the combined eddy tracking, contour-identification and eddy removal process is thought to underestimate the magnitude of eddies. As discussed in section 2, this results primarily from the contour-identification and eddy removal process, in which eddy pixels are replaced with those of a smoothed interpolated field. The second limiting factor is that the algorithm incorrectly connects distinct features, resulting in more energy being attributed to eddies than is warranted. Given a latent jet signal and eddies with comparable magnitudes, we might expect our confidence in the aforementioned percentages (i.e., 46-57\%) to decrease. To 
this end, we estimate bounds on the percentage of variance attributed to eddies using simulated eddies and jets.

[55] We simulated 16 years (1993-2008) of Gaussian eddies with positions, lifetimes and horizontal scales identically specified by the tracked eddy database and amplitudes specified by revised eddy amplitudes. We then applied the algorithm to the eddy-only data set. We find that approximately $27 \%$ of the simulated eddy variance is missed by the contour-identification and removal algorithm. Similarly, we simulated both eddies and stationary jets (the latter having amplitudes of $1 \mathrm{~cm}$ in dynamic height), and applied the algorithm to these fields. We find that the algorithm improperly attributes approximately $32 \%$ of the jet variance to eddies. Upper and lower bounds on the percentage of variance attributed to eddies can, therefore, be defined as $68 \%$ (lower) and $127 \%$ (upper) of $\sigma_{\bar{u}_{\text {eddy }}}^{2} / \sigma_{\bar{u}_{\text {total }}}^{2}$. In conjunction with values specified in Table 2, this suggests $31-72 \%$ of the total variance in the striation signal can be explained by eddies. While broad, these bounds on the variance attributable to eddies describe important aspects of the striation signal. They demonstrate that eddies account for an appreciable fraction of the striation signal (at least $31 \%$ ) but do not account for all of the jet-like signal (at most $72 \%$ ). While eddies in this study have been defined as those with lifetimes $\geq 4$ weeks, we believe that the variance in the striation signal decreases with decreasing eddy lifetime. This may point to the existence of latent $\beta$-plumes and/or MZJs.

[56] It is notable that two plume-like structures are observed in ADT near $27^{\circ} \mathrm{S}-30^{\circ} \mathrm{S}, 225^{\circ} \mathrm{E}-232^{\circ} \mathrm{E}$ (Figure 4a). Jet-like plumes such as these might result from radiating instabilities of an eastern boundary current [Hristova et al., 2008; Wang et al., 2012], but given the distance from the South American coast, it is more likely the result of intense flow past seamounts [Rhines, 1994] or island archipelagos.

\subsection{The Contribution of Eddies to Striations in SST}

[57] We close this study with a reference to striations in a secondary data set.
[58] Figure 12 displays time-averaged SST during 2005-2008, where SST measurements are those from the Advanced Microwave Scanning Radiometer for the Earth Observing System and have been spatially high-pass-filtered in the same manner as ADT. One notes the existence of zonal patterns in SST much like those seen in ADT. Indeed, contours of time-averaged ADT (2005-2008) coincide with contours in SST. The correlation coefficient between the two fields is 0.54 and increases when ADT is shifted west of its present location (not shown), implying that SST and ADT are highly correlated but that mesoscale SST anomalies lie west, on average, of mesoscale anomalies in ADT.

[59] These results are consistent with earlier studies examining the relationship between SST and SSH in the North Pacific [Roemmich and Gilson, 2001; Qiu and Chen, 2005] and we note that a similar correlation and spatial offset have been found to exist between surface chlorophyll concentration and SLA in the South Pacific [Chelton et al., 2011b]. Given the role of eddies in forming striations in ADT and given moderate correlation values between SST and ADT, it is likely that eddies contribute substantially to striations in SST. Similar arguments might be made for patterns observed in density fields derived from Argo floats [van Sebille et al., 2011; Cravatte et al., 2012] and wind measurements over the ocean surface [Maximenko et al., 2010; Divakaran, 2011], given an observed relationship between upper ocean density anomalies and eddies [Roemmich and Gilson, 2001; Qiu and Chen, 2005] and surface winds and eddies [Park et al., 2006; Small et al., 2008; Chelton and Xie, 2010], respectively.

[60] It is also notable that the striation signal in both SST and ADT appear to be influenced by bottom topography. This is evident in Figure 12, where bathymetric features shallower than $2500 \mathrm{~m}$ are overlaid in black. Note that large values of mean SST and ADT are observed east of the East Pacific Rise (running approximately north-south at $245^{\circ} \mathrm{E}-250^{\circ} \mathrm{E}$ ) and striations in both data sets appear influenced by subsurface archipelagos - for example, those bathymetric features extending northwest from Easter Island $\left(26^{\circ} \mathrm{S}, 250^{\circ} \mathrm{E}\right)$. It is likely that eddy tracks [Schlax and

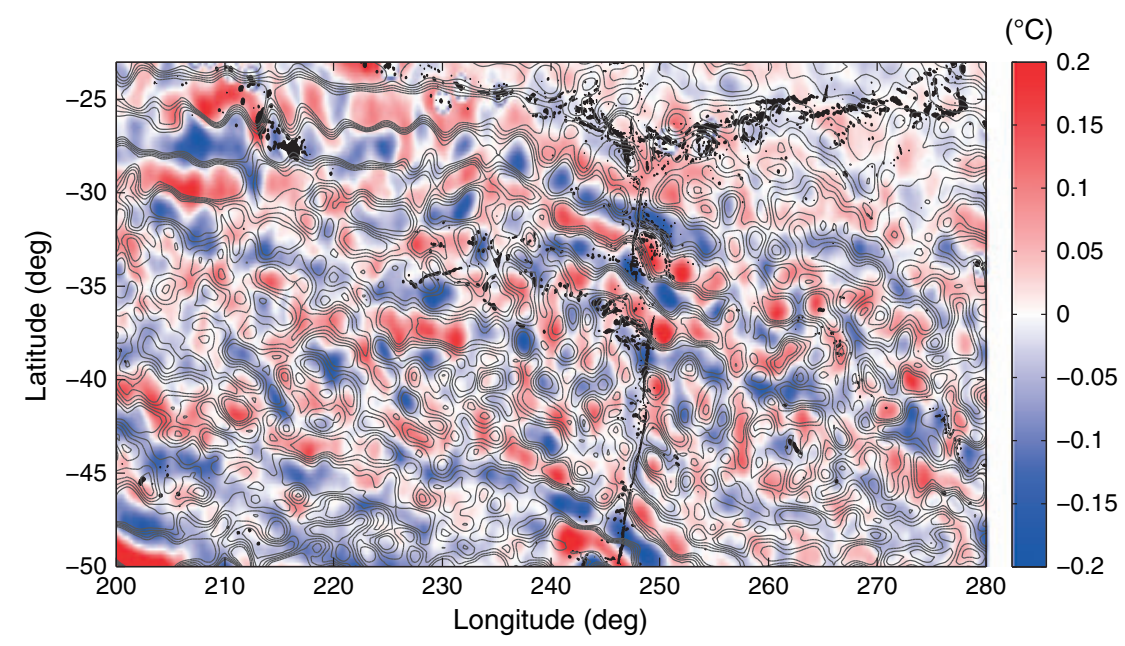

Figure 12. Time-averaged SST (2005-2008) with contours of time-averaged ADT (2005-2008) overlaid. Contours are given every $0.5 \mathrm{~cm}$ between -1 and $1 \mathrm{~cm}$ and both SST and ADT fields have been spatially high-pass-filtered in a manner following Maximenko et al. [2008]. Bathymetric features shallower than $2500 \mathrm{~m}$ are highlighted in black. 


\section{BUCKINGHAM AND CORNILLON: STRIATIONS IN ABSOLUTE DYNAMIC TOPOGRAPHY}

Chelton, 2008, Figure 1a] reveal the influence of bottom topography, as well. Such arguments support the concept of preferred pathways for eddies [Scott et al., 2008; Maximenko et al., 2008] and may help explain the observed decay of $\sigma_{\bar{u}}$ with averaging period.

[61] Acknowledgments. We wish to thank the following individuals for valuable contributions to this study: Dudley Chelton, Michael Schlax, Nikolai Maximenko, and Oleg Melnichenko. In addition, we are grateful for conversations with Prasanth Divakaran, Tom Farrar, Pavel Berloff, Shafer Smith, Patrice Klein, and Lewis Rothstein. Finally, we wish to thank three anonymous reviewers for helpful comments and criticism on an early draft of this manuscript. ADT were produced by Segment for ALTimetry, Orbitography and precise localisation/Developing Use of Altimetry for Climate Studies (SSALTO/DUACS) and distributed by Archivage, Validation, Interpretation des donnees des Satellite Oceanographiques (AVISO)/Collecte Localisation Satellites (CLS) with support from Centre National d'Etudes Spatiales (CNES). The database of tracked eddies was developed by Chelton and Schlax and is available at http://cioss.coas.oregonstate.edu/eddies/. Microwave SST measurements were provided by Chelle Gentemann of Remote Sensing Systems (RSS). This research has been made possible through a grant (NNX10AN69H) from the National Aeronautics and Space Administration.

\section{References}

Afanasyev, Y. D., S. O’Leary, P. B. Rhines, and E. Lindahl (2012), On the origin of jets in the ocean, Geophys. Astrophys. Fluid Dyn., 106(2), 113-137.

Baldwin, M. P., P. B. Rhines, H.-P. Huang, and M. E. McIntyre (2007), The jetstream conundrum, Science, 315, 467-468, doi:10.1126/science.1131375.

Bendat, J. S., and A. G. Piersol (2000), Random Data: Analysis and Measurement Procedures, Wiley Series in Probability and Statistics, 3rd ed. 594 pp., John Wiley and Sons, New York.

Berloff, P., I. Kamenkovich, and J. Pedlosky (2009), A mechanism of formation of multiple zonal jets in the oceans, J. Fluid Mech., 628, 395-425, doi:10.1017/S0022112009006375.

Berloff, P., S. Karabasov, J. T. Farrar, and I. Kamenkovich (2011), On latency of multiple zonal jets in the oceans, J. Fluid Mech., 686, 534-567, doi:10.1017/jfm.2011.345.

Beron-Vera, F. J., M. J. Olascoaga, G. J. Goni, 2010: Surface ocean mixing inferred from different multisatellite altimetry measurements, J. Phys. Oceanogr., 40, 2466-2480, doi:10.1175/2010JPO4458.1.

Buckingham, C., and P. Cornillon (2010), Observed quasi-zonal banded structures in SST frontal probability: why do we see them?, Ocean Sciences 2010 Conference, Portland, Oregon.

Centurioni, L., J. Ohlmann, and P. Niiler (2008), Permanent meanders in the California Current System, J. Phys. Ocean., 38, 1690-1710, doi:10.1175/ 2008JPO3746.1.

Chelton, D. B., and M. G. Schlax (1996), Global observations of oceanic Rossby waves, Science, 272, 234-238.

Chelton, D. B., J. C. Ries, B. J. Haines, L.-L. Fu, and P. S. Callahan (2001), Satellite altimetry, in Satellite Altimetry and Earth Sciences: A Handbook of Techniques and Applications, edited by L.-L. Fu and A. Cazenave, pp. 1-131, Academic, San Diego, Calif.

Chelton, D. B., M. G. Schlax, R. M. Samelson, and R. A. de Szoeke (2007), Global observations of large oceanic eddies, Geophys. Res. Lett., 34, L15606, doi:10.1029/2007GL030812.

Chelton, D. B., and S.-P. Xie (2010), Coupled ocean-atmosphere interaction at oceanic mesoscales, Oceanog., 23(4), 52-69, doi:10.5670/oceanog.2010.05.

Chelton, D. B., M. G. Schlax, and R. M. Samelson (2011a), Global observations of nonlinear mesoscale eddies, Prog. Oceanog., 91, 167-216, doi:10.1016/j.pocean.2011.01.002.

Chelton, D. B., P. Gaube, M. G. Schlax, J. J. Early, and R. M. Samelson (2011b), The influence of nonlinear mesoscale eddies on near-surface oceanic chlorophyll, Science, 334(6054), 328-332.

Cheney, R., L. Miller, R. Agreen, N. Doyle, and J. Lillibridge (1994), TOPEX/ POSEIDON: the 2-cm solution, J. Geophys. Res., 99, 24 555-24 563, doi:10.1029/94JC02050.

Cho, J. Y-K., and L. M. Polvani (1996), The emergence of jets and vortices in freely evolving, shallow-water turbulence on a sphere, Phys. Fluids, 8 , 5531-1552.

Cravatte, S., and W. Kessler, and F. Marin (2012), Intermediate zonal jets in the tropical Pacific Ocean observed by Argo floats, J. Phys. Oceanogr., doi:10.1175/JPO-D-11-0206.1.

Di Lorenzo, E., A. Belmadani, H. Luo, O. Melnichenko, N. Schneider, and N. Maximenko (2012), The emergence of striations in the North Pacific circulation, Ocean Sciences 2012 Conference, Salt Lake City, Utah.
Divakaran, P. (2011), Mesoscale circulation and variability of the Indian Ocean, Ph.D. thesis, School of Earth Sc., Univ. of Melbourne, Melbourne, Australia. Divakaran, P., and G. B. Brassington (2011), Arterial ocean circulation of the southeast Indian Ocean, Geophys. Res. Lett., 38, L01802, doi:10.1029/2010GL045574.

Ducet, N., P. Y. LeTraon, and G. Reverdin (2000), Global high-resolution mapping of ocean circulation from TOPEX/Poseidon and ERS-1 and -2, J. Geophys. Res., 105, 477-498.

Firing, E. (1987), Deep zonal currents in the central equatorial Pacific, J. Mar. Res., 45, 791-812.

Gouriou, Y., T. Delcroix, and G. Eldin (1987), Upper and intermediate circulation in the western equatorial Pacific Ocean in October 1999 and April 2000, Geophys. Res. Lett., 33, L10603, doi:10.1029/2006GL025941.

Hogg, N. G., and W. Brechner Owens (1999), Direct measurement of the deep circulation within the Brazil Basin, Deep-Sea Res. II, 46, 335-353.

Holton, J. R. (1979), An Introduction to Dynamic Meteorology, 3rd ed., 391 pp., Elsevier Academic Press, San Diego.

Hristova, H. G., J. Pedlosky, and M. A. Spall (2008), Radiating instability of a meridional boundary current, J. Phys. Oceanogr., 38, 2294-2307, doi:10.1175/2008JPO3853.1.

Huang, H.-P., A. Kaplan, E. N. Curchitser, and N. A. Maximenko (2007), The degree of anisotropy for mid-ocean currents from satellite observations and an eddy-permitting model simulation, J. Geophys. Res., 36, C09005, doi:10.1029/2007JC004105.

Ivanov, L., C. Collins, and T. Margonina (2009), System of quasi-zonal jets off California revealed from satellite altimetry, Geophys. Res. Lett., 36, L03609, doi:10.1029/2008GL036327.

Ivanov, L., C. Collins, T. Margonina, and V. Eremeev (2010), Nonlinear Rossby waves off California, Geophys. Res. Lett., 37, L13602, doi:10.1029/2010GL043708.

Kamenkovich, I., P. Berloff, and J. Pedlosky (2009), Role of eddy forcing in the dynamics of multiple zonal jets in a model of the North Pacific, J. Phys. Ocean., 39, 1361-1379, doi:10.1175/2008JPO4096.1.

Le Traon, P. Y., Y. Faugère, F. Hernandez, F. M. J. Dorandeu, and M. Ablain (2003), Can we merge GEOSAT follow-on with TOPEX/Poseidon and ERS-2 for an improved description of the ocean circulation?, J. Atmos. Oceanic Technol., 20, 889-895.

Maltrud, M. E., and G. K. Vallis (1991), Energy spectra and coherent structures in forced two-dimensional and beta-plane turbulence, J. Fluid Mech., 228, 321-342, doi:10.1017/S0022112091002720.

Martin, S. (2004), An Introduction to Ocean Remote Sensing, 426 pp., Cambridge University Press, Cambridge.

Maximenko, N., B. Bang, and H. Sasaki (2005), Observational evidence of alternating zonal jets in the World Ocean, Geophys. Res. Lett., 32, L12607, doi:10.1029/2005GL022728.

Maximenko, N., O. V. Melnichenko, P. P. Niiler, and H. Sasaki (2008), Stationary mesoscale jet-like features in the ocean, Geophys. Res. Lett., 35, L08603, doi:10.1029/2008GL033267.

Maximenko, N., O. V. Melnichenko, S.-P. Xie, and N. Schneider (2010), Atmospheric signatures of oceanic striations, poster, Altimetry for Oceans and Hydrology - OSTST Meeting, Lisbon, Portugal.

Melnichenko, O. V., N. A. Maximenko, N. Schneider, and H. Sasaki (2010), Quasi-stationary striations in basin-scale oceanic circulation: vorticity balance from observations and eddy-resolving model, Ocean Dyn., 60, 653-666.

Nakano, H., and H. Hasumi (2005), A series of zonal jets embedded in the broad zonal flows in the Pacific obtained in eddy-permitting ocean general circulation models, J. Phys. Ocean., 35, 474-488.

Nowlin, W. D. , Jr. and M. Clifford (1982), The kinematic and thermohaline zonation of the Antarctic Circumpolar Current at Drake Passage, J. Mar. Res., 40, 481-507.

Orsi, A. H., T. Whitworth, III, and W. D. Nowlin, Jr. (1995), On the meridional extent and fronts of the Antarctic Circumpolar Current, Deep-Sea Res. I, 42, 641-673.

Panetta, R. L. (1993), Zonal jets in wide baroclinically unstable regions: persistence and scale selection, J. Atmos. Sci., 50, 2073-2106.

Park, K., P. Cornillon, and D. L. Codiga (2006), Modification of surface winds near ocean fronts: Effects of Gulf Stream rings on scatterometer (QuikSCAT, NSCAT) wind observations, J. Geophys. Res., 111, C03021, doi:10.1029/2005JC003016.

Pascual, A., Y. Faugère, G. Larnicol, and P.-Y. Le Traon (2006), Improved description of the ocean mesoscale variability by combining four satellite altimeters, Geophys. Res. Lett., 33, L02611, doi:10.1029/2005GL024633.

Pedlosky, J. (1975), On secondary baroclinic instability and the meridional scale of motion in the ocean, J. Phys. Ocean., 5, 603-607.

Qiu, B., and S. Chen (2005), Eddy-induced heat transport in the subtropical North Pacific from Argo, TMI, and altimetry measurements, J. Phys. Ocean., 35, 458-473.

Rhines, P. B. (1975), Waves and turbulence on a beta-plane, J. Fluid Mech. $69,417-443$. 


\section{BUCKINGHAM AND CORNILLON: STRIATIONS IN ABSOLUTE DYNAMIC TOPOGRAPHY}

Rhines, P. B. (1994), Jets, Chaos, 4, 313-339.

Rio, M. H., S. Guinehut, and G. Larnicol (2011), New CNES-CLS09 global mean dynamic topography computed from the combination of GRACE data, altimetry, and in situ measurements, J. Geophys. Res., C07018, doi:10.1029/2010JC006505

Roemmich, D., and J. Gilson (2001), Eddy transport of heat and thermocline waters in the North Pacific: a key to interannual/decadal climate variability?, J. Phys. Ocean., 31, 675-687.

Schlax, M. G., and D. B. Chelton (2008), The influence of mesoscale eddies on the detection of quasi-zonal jets in the ocean, Geophys. Res. Lett., 35 , L24602, doi:10.1029/2008GL035998.

Scott, R. B., B. K. Arbic, C. L. Holland, A. Sen, and B. Qiu (2008), Zonal versus meridional velocity variance in satellite observations and realistic and idealized ocean circulation models, Ocean Modell., 23, 102-112, doi:10.1016/j.ocemod.2008.04.009.

Small, R. J., S. P. de Szoeke, S. P. Xie, L. O’Neill, H. Seo, Q. Song, P. Cornillon, M. Spall, S. Minobe (2008), Air-sea interaction over fronts and eddies, Dyn. Atm. Oceans, 45, 274-319, doi:10.1016/j.dynatmoce.2008.01.001.
Sokolov, S., and S. R. Rintoul (2007), Multiple jets of the Antarctic Circumpolar Current south of Australia, J. Phys. Ocean., 37, 1394-1412, doi:10.1175/JPO3111.1.

Treguier, A. M., and R. L. Panetta (1994), Multiple zonal jets in a quasigeostrophic model of the Antarctic Circumpolar Current, J. Phys. Oceanogr., 24, 2263-2277.

van Sebille, E., I. Kamenkovich, and J. K. Willis (2011), Quasi-zonal jets in 3D Argo data of the northeast Atlantic, Geophys. Res. Lett., 38, L02606, doi:10.1029/2010GL046267.

Wang, J., M. A. Spall, G. R. Flierl, and P. Malanotte-Rizzoli (2012), A new mechanism for the generation of quasi-zonal jets in the ocean, Geophys. Res. Lett., 39, L10601, doi:10.1029/2012GL051861.

Williams, G. P. (1978), Planetary circulations: 1. Barotropic representation of Jovian and terrestrial turbulence, J. Atmos. Sci., 35, 1399-1426.

Wunsch, C., and D. Stammer (1998), Satellite altimetry, the marine geoid, and the ocean general circulation, Annu. Rev. Earth Planet. Sci., 26, 219-253. 